\title{
INHIBITION OF CONIDIUM GERMINATION AND MYCELIAL GROWTH OF BOTRYTIS CINEREA BY NATURAL PRODUCTS
}

\author{
A. ANTONOV, A. STEWART and M. WALTER ${ }^{1}$
}

\author{
Department of Plant Science, P.O. Box 84, \\ Lincoln University, Canterbury, New Zealand; \\ ${ }^{I}$ The Horticulture \& Food Research Institute of New Zealand Ltd., \\ Canterbury Agriculture Science Centre, Lincoln, Canterbury, New Zealand
}

\begin{abstract}
Using in vitro tests, 21 oil extracts were assessed at $0.1,1.0$ and $10 \%$ concentrations for effects on conidium germination, germtube elongation and mycelial growth in Botrytis cinerea. Reduction $(\mathrm{P} \leq 0.05)$ of conidium germination and germtube length was achieved at $0.1 \%$ concentration with extracts of thyme R (Thymus capitatus) (100\% and $100 \%$ respectively), clove (Syzygium aromaticum) (67\% and $93 \%$ respectively) and Australian minttree (Prostanthera rotundifolia) (65\% and 65\% respectively). Thyme R oil and Trichoderma harzianum metabolites 6pentyl-alpha-pyrone (6-PAP) and a 6-PAP derivative, gave the greatest inhibition of mycelial growth of the extracts tested at $10 \%$ concentration.

Keywords: Botrytis cinerea, 6-PAP, thyme oil, clove oil
\end{abstract}

\section{INTRODUCTION}

Botrytis cinerea Pers.:Fr. is an economically important pathogen of a wide range of economic plants. Recent research has focused on the search for novel compounds active against this fungus which may have potential in disease control. Some natural compounds have already been identified. Wilson et al. (1987) detected a number of volatile compounds derived from peach plant extracts (benzaldehyde, methyl salicilate, ethyl benzoate) that completely inhibited the growth of B. cinerea and Monilinia fructicola (Winter) Honey. Caccioni and Guizzardi (1994) reported that nine oil extract components inhibited germination and growth of a wide range of postharvest pathogenic fungi such as B. cinerea, Monilinia laxa (Aderh. \& Ruhl.) Honey, Mucor piriformis Fischer, Rhizopus stolonifer (Ehrenb.) Lind and three Penicillium spp. Oil extracts from thyme (Thymus capitatus) (Arras et al. 1995), sage (Silva officinalis)(Carta et al. 1996), marjoram (Oreganum syriacum), lavender (Lavandula angustifolia), lemongrass (Cymbopogon citratus) (Shimonietal. 1993), tea tree (Melaleuca alternifolia), melissa (Melissa officinalis), peppermint (Mentha piperita), penny royal (Mentha pulegium), jasmine (Jasminum grandiflorum), bois de rose (Rosa spp.), neroll (Citrus aurantum sub.aurantum), wintergreen (Gaultheria procumbens) and hyssop (Hyssopus officinalis) (Cutler et al.1996), all inhibited in vitro mycelial growth of B. cinerea.

In this study 21 extracts (19 plant oil extracts and two microbial metabolites) were tested for activity against B. cinerea in laboratory tests, as the first step towards development of a biological control system for control of Botrytis bunch rot of grapes.

\section{METHODS \\ Origin of $B$. cinerea isolate and inoculum production}

B. cinerea isolate B4, obtained from the Lincoln University Culture Collection, was originally isolated from grape leaf tissue in Marlborough in 1995. The isolate was grown on oatmeal agar (30 g oat meal, $20 \mathrm{~g}$ agar/litre) at ambient temperature under a light bank with photoperiod $12 \mathrm{~h}$ light/12 h dark. Conidia were harvested from 14 day-old cultures. Ten $\mathrm{ml}$ of $0.05 \%$ Tween 80 in sterile distilled water (SDW) was added to each plate and the conidia were dislodged by rubbing the surface area with a glass rod. The washings

Proc. 50th N.Z. Plant Protection Conf. 1997: 159-164 
were then filtered through a layer of lens cleaning tissue (Whatman) to remove the mycelial fragments. Conidia were pelleted by centrifugation at $3000 \mathrm{rpm}$ for $2 \mathrm{~min}$. The supernatant was discarded and the pellet re-suspended in $0.05 \%$ Tween 80 in SDW and mixed for a few seconds, this process was repeated three times. The number of conidia were determined with a haemocytometer (Reichert) and adjusted to $1 \times 10^{5}$ conidia $/ \mathrm{ml}$. Origin of oil extracts

Five oil extracts, rosemary (Rosmarinus officinalis), plant extract Mo 95/024, stinking roger (Tagetes minuta), manuka (Leptospermium scoparium), Australian minttree (Prostanthera rotundifolia), were provided by Dr. P. Smaile (NZ Institute for Crop \& Food Research Ltd., Riwaka). Ten oil extracts, tea tree R (Melaleuca alternifolia), thyme R (Thymus capitatus), peppermint (Mentha piperita), jasmine (Jasminum grandiflorum), bois de rose (Rosa spp.), penny royal (Mentha pulegium), lemongrass (Cymbopogon citratus), lavender cv. Mt. Blanc (Lavandula angustifolia), and T. harzianum metabolites 6-PAP and a 6-PAP derivative, were obtained from Dr. R.A. Hill (The Horticulture and Food Research Institute of NZ Ltd., Ruakura). The following four oil extracts from clove (Syzygium aromaticum) (BDH Chemicals Ltd., Poole, England) cedarwood (Cedrus spp.; George T.Gurr Ltd., London, England), tea tree J (Melaleuca alternifoliaI; Healtheries of NZ Ltd., Auckland), thyme J (Thymus capitatus; Thyme Cottage, Christchurch), together with two cooking oils, olive oil (William Aitken and Co., Lower Hutt) and sesame oil (Yeo Hiap Seng Ltd., Singapore) were commercially available.

\section{Preparation of extract suspensions}

A number of homogenising agents for dilution of the oil extracts were tested. Down to Earth washing liquid (Reckett and Colman NZ Ltd, Auckland) used as a SDW based $0.042 \%$ solution was selected for all tests. This concentration had no effect on conidium germination or germtube growth of $B$. cinerea. The extracts were used at concentrations of $0.1,1.0$ and $10 \%$. To suspend and homogenise the oils the final concentrations were mixed for 1 min with high speed homogeniser (Ultra Turrax) and used immediately.

\section{Effects of extracts on conidium germination and germtube growth}

Potato Dextrose Agar (PDA; Merck) was poured into petri plates $20 \mathrm{ml} / \mathrm{plate}$. Agar plugs were cut with a sterile cork borer ( $10 \mathrm{~mm}$ diameter) and placed into petri dishes (3 plugs/dish). An aliquot of $30 \mu \mathrm{l}$ of $B$. cinerea conidium suspension was then pipetted onto the surface of each agar plug. Plugs were dried for $10 \mathrm{~min}$ followed by application of 30 $\mathrm{ml} / \mathrm{plug}$ of the test extract at one of the three concentrations $(0.1,1$ and $10 \%)$. Botrytis control received $30 \mu \mathrm{l} / \mathrm{plug}$ of $0.042 \%$ homogenising agent in SDW. Different extracts and different concentrations were tested in separate petri dishes to prevent interaction. The petri dishes were closed immediately to prevent unnecessary evaporation or interaction in the case of extracts containing volatile components, sealed with plastic film and incubated at $20^{\circ} \mathrm{C}$ and $12 \mathrm{~h}$ photoperiod. Sixteen hours after incubation, percentage germination of conidia was determined from counts of 100 conidia selected from a random sweep across the diameter of each agar plug. A conidium was considered germinated if the germtube length was equal to 1-1.5 times the length of the conidium. Average germtube length was determined on the basis of random measurement of five germtubes on each agar plug using microscope eyepiece graticule. To establish whether the effect of an extract on germination and germtube growth was long lasting, further observations were made after 3, 6 and 30 days.

\section{Effects of extracts on mycelial growth}

PDA was autoclaved and cooled in a waterbath to $48^{\circ} \mathrm{C}$, at which time Botrytis conidium suspension was mixed into the agar to provide a final concentration of $1 \times 10^{5}$ conidia/ml. The seeded PDA was then poured into petri dishes $(20 \mathrm{ml} / \mathrm{plate})$ using a sterilised manual dispenser. Three $30 \mathrm{ml}$ drops of each test suspension $(0.042 \%$ homogenising agent in SDW forBotrytiscontrol) were then equally spaced onto the agar surface. The different test substances and concentrations were tested in separate petri dishes to prevent interaction. The lid of each individual petri dish was replaced immediately to prevent unnecessary evaporation or interaction and sealed with plastic film. All plates were incubated at $20^{\circ} \mathrm{C}$ and $12 \mathrm{~h}$ photoperiod and assessed after three days of incubation. Plates were examined for the presence of a zone of inhibition where the 
test substance was applied and the diameters of the zones were measured.

In both tests, each treatment (extract, concentration) and the Botrytis control consisted of three replicate petri dishes. A block design was adopted during incubation to prevent interaction between volatile fractions in the test extracts. Experiments were carried out in duplicate.

\section{Statistics}

Statistical analyses of all experimental data were done using the statistical software package SYSTAT 6. Analysis of variance was followed by comparison of means for significant effect using LSD. Differences were considered to be significant at $\mathrm{P} \leq 0.05$.

\section{RESULTS AND DISCUSSION}

The effects of the 10 extracts that had the greatest antifungal effects, of the 21 tested, on conidium germination and germtube growth of $B$. cinerea are presented in Tables 1 and 2 . Both conidium germination and germtube growth were reduced by these extracts and the extract concentration effect was statistically significant $(\mathrm{P}<0.001)$. Conidium germination in the controls was $>96 \%$ and germtube growth was $>37 \mathrm{~mm}$. The most effective extract was Thyme R oil which completely inhibited conidium germination and germtube growth at the lowest concentration tested $(0.1 \%)$. At the same concentration, clove oil reduced germination and germtube growth by $67 \%$ and $93 \%$ respectively, while Prostanthera oil reduced conidium germination and germtube growth by $65 \%$ and $65 \%$ respectively. Both clove and Prostanthera oils were equally effective in suppressing germination at $0.1 \%$, but suppression of germtube growth was greater with clove oil. Prostanthera oil did not completely inhibit germination at $1 \%$ and $10 \%$ concentration but reduced germination by $86 \%$ and $99 \%$ respectively. Mo95/024 plant oil extract and theTrichoderma metabolites, 6-PAP and 6-PAP-derivative completely inhibited conidium germination and germtube growth at $1 \%$ concentration. Although some extracts failed to inhibit germination at $0.1 \%$ concentration, they inhibited germtube growth (eg. manuka, tea tree $\mathrm{R})$.
TABLE 1: Mean percentage germination of Botrytis cinerea conidia at three concentrations of oil extracts after $16 \mathrm{~h}$ of incubation on PDA at $20^{\circ} \mathrm{C}$.

\begin{tabular}{lccc}
\hline Extracts & \multicolumn{3}{c}{$\begin{array}{c}\text { Concentration } \\
1.0 \%\end{array}$} \\
\hline Nil & $0.1 \%$ & $10.0 \%$ \\
Thyme R & $96 \mathrm{f}^{1}$ & $95 \mathrm{e}$ & $97 \mathrm{~b}$ \\
Clove & $0 \mathrm{a}$ & $0 \mathrm{a}$ & $0 \mathrm{a}$ \\
Prostanthera & $32 \mathrm{~b}$ & $0 \mathrm{a}$ & $0 \mathrm{a}$ \\
Mo 95/024 & $33 \mathrm{~b}$ & $14 \mathrm{c}$ & $1 \mathrm{a}$ \\
Manuka & $78 \mathrm{c}$ & $0 \mathrm{a}$ & $0 \mathrm{a}$ \\
6-PAP & $86 \mathrm{~d}$ & $1 \mathrm{a}$ & $0 \mathrm{a}$ \\
6-PAPderivative & $89 \mathrm{e}$ & $0 \mathrm{a}$ & $0 \mathrm{a}$ \\
Bois De Rose & $89 \mathrm{e}$ & $0 \mathrm{a}$ & $0 \mathrm{a}$ \\
Tea tree R & $95 \mathrm{f}$ & $0 \mathrm{a}$ & $0 \mathrm{a}$ \\
Lavander & $95 \mathrm{f}$ & $0 \mathrm{a}$ & $0 \mathrm{a}$ \\
Rosemary & $95 \mathrm{f}$ & $0 \mathrm{a}$ & $0 \mathrm{a}$ \\
Jasmine & $96 \mathrm{f}$ & $0 \mathrm{a}$ & $0 \mathrm{a}$ \\
\end{tabular}

${ }^{1}$ Means within columns followed by the same letter are not different $(\mathrm{P} \leq 0.05)$ as tested by LSD. Data are pooled results of two experiments.

From the remaining nine extracts (not presented in Table 1 and Table 2) none had affected conidium germination at $0.1 \%$ concentration. Four extracts (tea tree J, lemongrass, peppermint and penny royal) at $1 \%$ concentration reduced germination by $75 \%, 63 \%$, $55 \%$ and $33 \%$ respectively. Together with Tagetes oil these extracts completely suppressed germination at $10 \%$ concentration. At $10 \%$ concentration, cedar, sesame and 
olive oils gave germination not different to the controls, while thyme $\mathrm{J}$ oil reduced germination $(77 \%)$.

At $0.1 \%$ concentration, only thyme $J$, cedar and tea tree $\mathrm{J}$ oils gave reduced germtube length (with growth of $17 \mathrm{~mm}, 19 \mathrm{~mm}$ and $25 \mathrm{~mm}$ respectively), while at $1 \%$ and $10 \%$ concentration all but sesame and olive oils affected germtube growth.

Observations carried out on the 6th day revealed mycelial growth on the $0.1 \%$ Thyme R oil plates starting from the edge of the agar plug. On the 30th day, plates from all test extracts at all concentrations, with the exception of $1 \%$ and $10 \%$ clove oil exhibited some germination and mycelial growth of Botrytis, thus suggesting fungistatic activity of these extracts at $10 \%$ and lower concentrations.
TABLE 2: Mean germtube length $(\mu \mathrm{m})$ of Botrytis cinerea conidia at three concentrations of oil extracts after $16 \mathrm{~h}$ of incubation on PDA at $20^{\circ} \mathrm{C}$.

\begin{tabular}{lccc}
\hline Extracts & \multicolumn{3}{c}{$\begin{array}{c}\text { Concentration } \\
1.0 \%\end{array}$} \\
\hline Nil & $0.1 \%$ & $10.0 \%$ \\
Thyme R & $37 \mathrm{~g}^{1}$ & $41 \mathrm{c}$ & $38 \mathrm{c}$ \\
Clove & $0 \mathrm{a}$ & $0 \mathrm{a}$ & $0 \mathrm{a}$ \\
6-PAPderivative & $3 \mathrm{~b}$ & $0 \mathrm{a}$ & $0 \mathrm{a}$ \\
6-PAP & $3 \mathrm{bc}$ & $0 \mathrm{a}$ & $0 \mathrm{a}$ \\
Tea tree R & $4 \mathrm{c}$ & $0 \mathrm{a}$ & $0 \mathrm{a}$ \\
Manuka & $9 \mathrm{~d}$ & $3 \mathrm{~b}$ & $0 \mathrm{a}$ \\
Prostanthera & $10 \mathrm{~d}$ & $6 \mathrm{~b}$ & $0 \mathrm{a}$ \\
Mo 95/024 & $13 \mathrm{e}$ & $10 \mathrm{~b}$ & $7 \mathrm{~b}$ \\
Lavander & $14 \mathrm{e}$ & $0 \mathrm{a}$ & $0 \mathrm{a}$ \\
Bois De Rose & $31 \mathrm{f}$ & $5 \mathrm{~b}$ & $0 \mathrm{a}$ \\
Rosemary & $35 \mathrm{~g}$ & $2 \mathrm{~b}$ & $0 \mathrm{a}$ \\
Jasmine & $35 \mathrm{~g}$ & $5 \mathrm{~b}$ & $0 \mathrm{a}$ \\
& $36 \mathrm{~g}$ & $3 \mathrm{~b}$ & $0 \mathrm{a}$ \\
\hline
\end{tabular}

${ }^{1}$ Means within columns followed by the same letter are not different $(\mathrm{P} \leq 0.05)$ as tested by LSD. Data are pooled results of two experiments.

Statistically significant reductions in mycelial growth and interaction between extracts and experiments were detected at $\mathrm{P}<0.001$ for all six extracts which showed inhibition zones. No inhibition zones were evident for any extract tested at $0.1 \%$ and $1 \%$ with the exception of 6-PAP which gave a small inhibition zone $(1.9 \mathrm{~mm})$ at $1 \%$. Results for $10 \%$ concentration are presented in Table 3 . The most inhibitory extract across replicate experiments was 6-PAP-derivative followed by Thyme R oil (not different from 6-PAP-derivative in Experiment 1), and 6-PAP (not different from 6-PAP-derivative in Experiment 2).

Our results clearly show strong antifungal activity for Thyme R oil and 6-PAP towards B. cinerea, confirming those reported by Arras et al. (1995) and Hill (1994). The Trichoderma metabolite 6-PAP has also been shown elsewhere to be fungistatic (Hill 1994). Our results also demonstrated that 6-PAP initially inhibited germination and mycelial growth of $B$. Cinerea; this effect diminished with time, suggesting that the control was fungistatic against the pathogen. Cutler et al. (1996) obtained similar results in a study of efficacy of 6-PAP against B. cinerea. They also reported that $100 \%$ concentration of thyme, tea tree, lavender, lemongrass, peppermint, penny royal, jasmine, bois de rose inhibited mycelial growth of $B$. cinerea. Our study confirmed the activity of these oils on suppression of Botrytis germination and germtube growth even at 100-fold dilution and also showed in similar experiments that thyme $\mathrm{R}$, lemongrass and penny royal (Table 3 ) retained activity inhibiting mycelial growth at 10 -fold dilution.

TABLE 3: Mean diameter of inhibition zones ( $\mathrm{mm})$ produced onBotrytis cinerea 
seeded PDA after 3 days of incubation at $20^{\circ} \mathrm{C}$, by oil extracts at $10 \%$ concentration in replicate experiments.

\begin{tabular}{lcc}
\hline Extract $^{1}$ & Experiment 1 & Experiment 2 \\
\hline 6-PAPderivative & $25 \mathrm{~d}^{2}$ & $20 \mathrm{~d}$ \\
Thyme R & $23 \mathrm{~d}$ & $18 \mathrm{c}$ \\
6-PAP & $18 \mathrm{c}$ & $21 \mathrm{~d}$ \\
Lemongrass & $13 \mathrm{~b}$ & $10 \mathrm{~b}$ \\
Clove & $11 \mathrm{~b}$ & $8 \mathrm{a}$ \\
Penny royal & $4 \mathrm{a}$ & $11 \mathrm{~b}$ \\
\hline
\end{tabular}

${ }^{1}$ Only extracts where inhibition zone was observed are listed here.

${ }^{2}$ Means within columns followed by the same letter are not different $(\mathrm{P} \leq 0.05)$ as tested by LSD.

Thyme and Tea tree were represented in our experiments by two different brands, $\mathrm{R}$ and $\mathrm{J}$, that showed different levels of activity in both tests. At present, it is not clear whether the difference in activity can be explained by differences in purity of the oil extracts or the source of the plant material used to produce them. However, this indicates an important source of variability that is likely to affect the efficacy of the extracts.

Whilst clove oil and Prostanthera oil have been previously reported to possess fungicidal properties against several pathogenic fungi, such as Aspergillus parasiticus (Salmeron and Pozo 1991) and Cladosporium cucumerinum (Dellar et al. 1994), we have found no other reports on activity of these extracts towards B. cinerea. Mo95/024 is a plant-derived oil extract currently under investigation by researchers at the NZ Institute for Crop \& Food Research Ltd., Riwaka. To our knowledge, this is the first report of activity by this extract against $B$. cinerea.

The dicarboximide fungicide iprodione is commonly used to control many diseases caused by $B$. cinerea. At $0.25 \%$ concentration $(2.5 \mathrm{~g} /$ litre $)$ iprodione exhibits fungistatic action against this fungus (Cartaet al. 1996), a similar effect to that observed in this study for thyme R and clove oils and to lesser extent for 6-PAP-derivative, 6-PAP, Prostanthera and Mo95/024 oils. The efficacy of these extracts may differ in in vivo systems under the influence of environmental conditions. Isolate-specific reactions towards the extracts could also occur. Concentrations higher than $1 \%$ might prove uneconomic for field application, as some of the extracts are available only in small quantities. Phytotoxicity problems may arise when these extracts are applied to living plant tissues. However, the six extracts identified in this study have the potential to be effective for control of $B$. cinerea and will be further examined in glasshouse studies using Botrytis/grape as a model system.

\section{ACKNOWLEDGEMENTS}

We thank the Winegrowers of New Zealand for funding this research. We also thank Dr. Peter Smaile, Crop \& Food Research, Nelson, for oil extracts; Dr. Robert Hill for oil extracts, and literature; Joanne Perry, HortResearch, Lincoln and Leanne Perry-Meyer, HortResearch, Ruakura for technical advice and support; and Dr. Chris Frampton, Lincoln University, for statistical advice.

\section{REFERENCES}

Arras, G., Agabbio, M., Piga, A., D’hallewin, G., Gerasopoulos, D., Olympios, C. and Passam, H., 1995. Fungicide effect of volatile compounds of Thymus capitatus essential oil. Acta Horticulturae 379:593-600.

Caccioni, D.R.L. and Guizzardi, M., 1994. Inhibition of germination and growth of fruit and vegetable postharvest pathogenic fungi by essential oil components.J. Essential Oil Res. 6(2):173-179.

Carta, C., Moretti, M.D.L. and Peana, A.T., 1996. Activity of the oil of Silva officinalis L. against Botrytis cinerea. J. Essential Oil Res. 8(4):399-404. 
Cutler, H.G., Hill, R.A., Ward, B.G., Rohitha, B.H. and Stewart, A., 1996. Antimicrobial, insecticidal and medicinal properties of natural products, flavours and fragrances. Pp. 51-66 In: Biotechnologies for improved foods and flavours. G.R. Takeoka, R. Teranishi, P.J. Williams and A. Kobayashi (Eds.) American Chemical Society.

Dellar, J.E., Cole, M.D., Gray, A.I., Gibbons, S. and Waterman, P.G., 1994. Antimicrobial sesquiterpenes fromProstanthera aff.melissifolia and $P$. rotundifolia. Phytochem. 36(4):957-960.

Hill, R.A., 1994. Control of Botrytis cinerea (grey mould) with 6-pentyl-alpha-pyrone (6-PAP) in cool stored kiwifruit. Pp. 50In: Biological control of fruit diseases: a three day workshop on research, regulation and registration of biological control agents for use against fruit pathogens, 13-15 Sep.: programme and abstracts.

Salmeron, J. and Pozo, R., 1991. Effect of cinnamon (Cinnamomum zeylanicum) and clove (Eugenia caryophyllus) on growth and toxigenesis of Aspergillus gr.flavus. Microbiologie, Aliments, Nutrition 9(1):83-87.

Shimoni, M., Reuveni, R. and Ravid, U., 1993. Growth inhibition of plant pathogenic fungi by essential oils. Hassadeh 74(3):306-308.

Wilson, C.L., Franklin, J.D. and Otto, B. E., 1987. Fruit volatiles inhibitory toMonilinia fructicola and Botrytis cinerea. Pl. Disease 71:316. 